\title{
Power Exchange by Using Micro-grid Inverter with High-Voltage Gain for Photovoltaic Applications
}

\author{
M. R. Banaei and E. Salary
}

\begin{abstract}
In this paper, power exchange in a clean energy system using multi-stage converter based on combination of novel dc/dc converter and the nine-switch inverter is presented. Power exchange between grid and renewable energies is one advantage of smart grid. The nine-switch converter consists of a one capacitor link and nine semiconductor switches and it has two output ports. The proposed dc/dc converter has high gain. The presented systems connect photovoltaic energy sources to load and grid. In proposed structure photovoltaic source inject energy to load and grid. If the photovoltaic source can't feed the load, the grid can feed load through nine-switch converter. The simulation results by MATLAB/SIMULINK show ability of presented systems in power generation.
\end{abstract}

Index Terms-Photovoltaic, dc/dc converter, nine-switch converter, power exchange.

\section{INTRODUCTION}

Nowadays, the use of renewable energy and green sources is gaining attention. Photovoltaic (PV) systems and fuel cell (FC) are new source of energy that generates dc voltage [1], [2]. The dc/ac inverters are power electronic devices used to produce mains voltage ac power from voltage dc sources (battery, PV or FC)[3]. For the energy conversion, the typical converter is based on a multi-stage converter and specially two-stage converter. Two-stage configuration is mainly used because of its advantages of easy control since maximum power point tracking (MMPT) control and current injection control [3], [4]. For example in the PV system the first stage is a dc/dc boost type converter responsible for both extracting the MPPT and boosting the PV voltage to a value higher than the peak of the grid voltage. The second stage is a dc/ac inverter that generates a current to be either injected into the grid or to feed loads.

The last few years, however, have witnessed the introduction of novel technologies and concepts [5]. Power exchange between grid and renewable energies is one advantage of smart grid.

In this paper, a multi-stage micro-grid inverter topology is proposed based on new transformer less high gain dc/dc converter and nine switch inverter. The proposed $\mathrm{dc} / \mathrm{dc}$ converter has the advantage of high-voltage gain and uses partial power processing technique. In the dc/ac part of multi-stage converter, nine-switch inverter is used [6]-[9]. The structure of the nine-switch inverter is presented in Fig. 1.

Manuscript received April 16, 2015; revised August 12, 2015

M. R. Banaei is with the the Electrical Engineering Department, Azarbaijan Shahid Madani University, Tabriz, Iran (e-mail: m.banaei@azaruniv.edu, salari@azaruniv.edu).

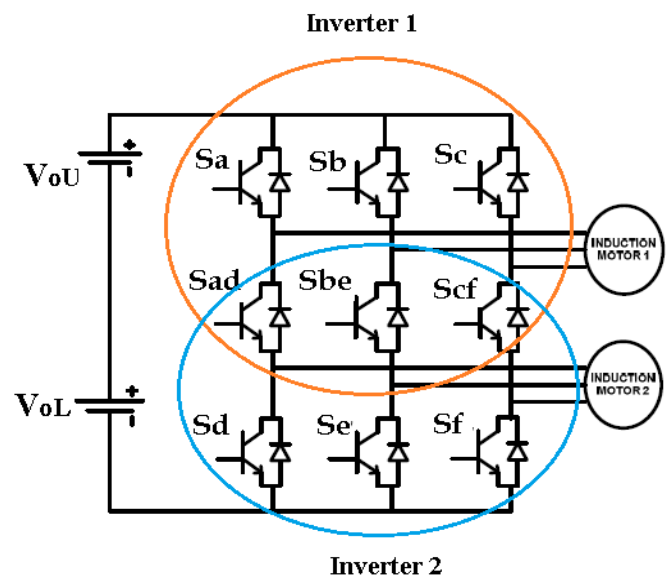

Fig. 1. Nine-switch inverter topology.

This consists of two three-phase inverters combined with three common switches. The Inverter 1 consists of switches $\mathrm{Sa}$, $\mathrm{Sb}, \mathrm{Sc}, \mathrm{Sad}$, Sbe, and Scf and Inverter2 consists of the switches Sad, Sce, Scf, Sd, Se and Sf. The balanced loads are supplied from these inverters. This topology has introduced for feeding two loads, in the first.

\section{Multi-STAGe DC/AC CONVERTER}

The proposed multi-stage inverter is shown in Fig. 2. The proposed system consists of novel dc/dc converter cascaded with nine-switch inverter. The $\mathrm{dc} / \mathrm{dc}$ converter has the advantage of high-voltage gain. The DC voltage generated from a single PV module has small value. These small DC values are not suitable to be used alone to produce the required ac voltage. Increasing the dc/ac conversion gain ratio by increasing the $\mathrm{dc} / \mathrm{dc}$ conversion gain ratio is one solution to overcome this problem. High efficiency is achieved by having a portion of the input PV power directly fed forward to the output without being processed by the converter. The boost converter switch $T_{1}$ is designed to operate at high frequency to decrease the inductor values and the overall system size.

\section{A. $d c / d c$ Converter}

Operation of $\mathrm{dc} / \mathrm{dc}$ converter is the same as conventional boost converter. This converter has two modes of operations. The output voltage is controlled by duty cycle of $T_{1}$ switch. $T_{1}$ switch has two states and by notice to switching state of $T_{1}$ switch, modes of operations are described as two modes. Fig. 3 shows two modes of dc/dc boost converter. Also, to simplify this analysis, the converter will be discussed assuming a simple resistive load $R$ is connected across its terminal instead and the resistance of semiconductors, inductors and capacitors are neglected. 


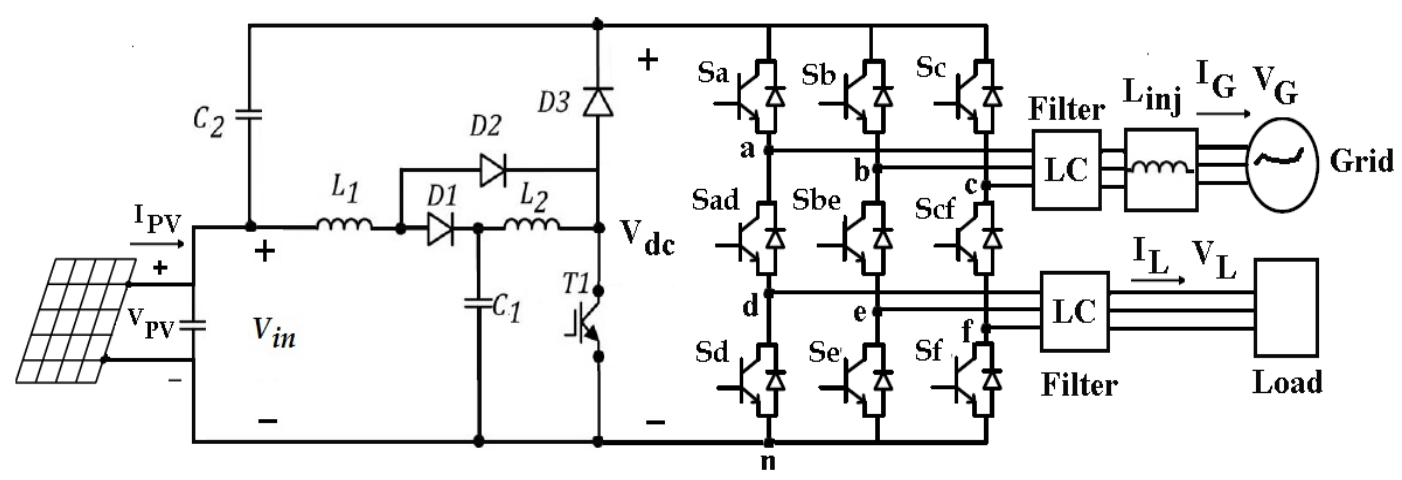

Fig. 2. Proposed multi-stage inverter.

The proposed converter operating in continuous conduction mode (CCM) and discontinuous conduction mode (DCM) but in this paper CCM mode is used because continuous input current is required for using in DG system.

First mode: Occurs when the switch $T_{1}$ is $\mathrm{ON}$, this causes diode $D_{2}$ to be turned $\mathrm{ON}$ and diodes $D_{1}$ and $D_{3}$ to be turned OFF. Thus the $L_{2}$ inductor and $C_{1}$ capacitor are parallel and the $L_{1}$ inductor and DC voltage source are parallel. In this mode inductors are charged. Fig. 3(a) shows the circuit of mode 1 . During mode 1 , the voltages across the inductors are

$$
\begin{aligned}
& V_{L 1}=V_{i n} \\
& V_{L 2}=V_{C 1}
\end{aligned}
$$

The duty cycle is:

$$
D=\frac{t_{0}}{T}=t_{0} \cdot f_{S}
$$

where $t_{0}, T$ and $f_{S}$ are the on switch time, period and switching frequency respectively.

Second mode: Occurs when the switch $T_{1}$ is OFF, this causes diode $D_{1}$ to be turned ON and diodes $D_{2}$ and $D_{3}$ to be turned OFF. Fig. 3(b) shows the circuit of mode 2.

$$
\begin{aligned}
& V_{L 1}=V_{i n}-V_{C 1} \\
& V_{L 2}=V_{C 1}-V_{d c}
\end{aligned}
$$

By notice the Eq. (1)-(5), the zero average inductors voltages over one carrier cycle are:

$$
\begin{aligned}
& \overline{V_{L 1}}=0=D V_{i n}+(1-D)\left(V_{i n}-V_{C 1}\right) \Rightarrow \\
& V_{i n}=(1-D) V_{C 1} \\
& \overline{V_{L 2}}=0=D V_{C 1}+(1-D)\left(V_{C 1}-V_{d c}\right) \Rightarrow \\
& V_{C 1}=(1-D) V_{d c}
\end{aligned}
$$

By replacing Eq. (6) in Eq. (7):

$$
V_{d c}=\frac{1}{(1-D)^{2}} V_{i n}
$$

The voltage of $C_{2}$ is obtained as:

$$
V_{C 2}=V_{d c}-V_{i n}=\frac{1}{(1-D)} V_{i n}
$$

The PV voltage and current are sensed and fed into the MPPT to generate the dc/dc converter switch $\left(T_{1}\right)$ pulses required to catch the maximum power from the $\mathrm{PV}$. The perturbation and observation $(\mathrm{P} \& \mathrm{O})$ algorithm with the merit of simplicity is used as a MPPT algorithm [10], [11].

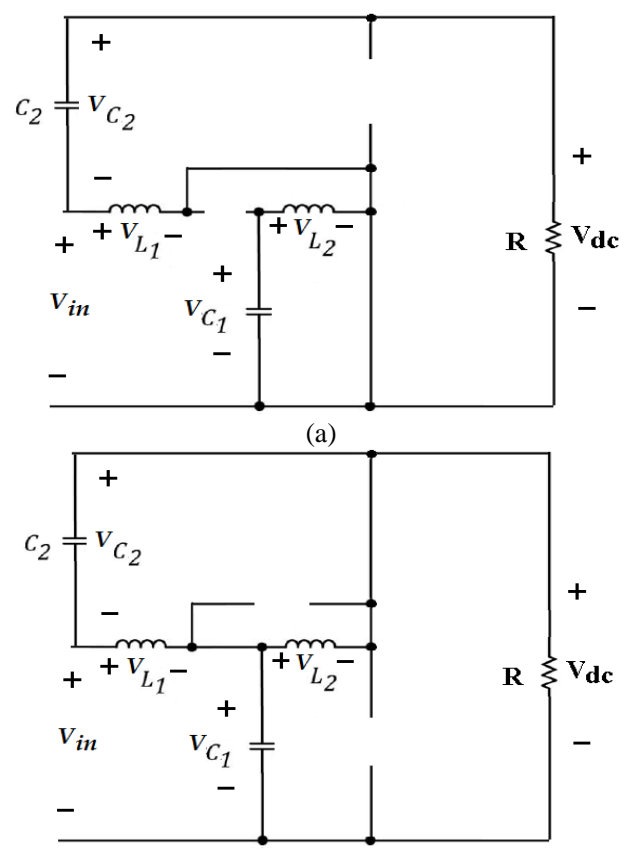

(b)

Fig. 3. Modes of DC-DC boost converter (a) mode 1 and (b) mode 2.

\section{B. dclac Converter}

The nine-switch inverter feed load and inject power to grid. In the proposed system, if PV energy system does not generate necessary energy to feed load, the grid feed load. This is increases power quality of overall system. The output voltages in nine-switch converter can be controlled independently. Switching states of one leg for nine-switch inverter are given in Table I. Fig. 4 shows modulation for one leg. In nine-switch inverter, PWM modulation unit needs six references waveforms [9]. A control technique should be designed for two inverters. One inverter works in grid tied mode and other work in islanding mode. Fig. 5 shows control 
block diagram of nine-switch inverter.

$$
P_{G}=P_{P V}-P_{L}
$$

where $P_{G}, P_{P V}$ and $P_{L}$ are power of grid, PV and load, respectively. In grid-connected state, voltage of dc-link $\left(V_{d c}\right)$ and inject current to the grid are measured and inject current transformed to $d-q$ frame using Park transformation. The dc-link $\left(V_{d c}\right)$ voltage is compared with reference value $\left(V_{d c}{ }^{*}\right)$. Resultant value is added to $\mathrm{d}$ axis component of inject current to the grid. The result is d component of reference wave. The $q$ axis component of inject current to the grid is compared with reference value $\left(i_{q G}{ }^{*}=0\right)$, the error signal is passed through PI controller. The result is $q$ component of reference wave. The generated $d$ and $q$ components transformed again to $a b c$ frame by Park inverse-transformation.

\begin{tabular}{lll}
\multicolumn{3}{l}{ TABLE I: } \\
\hline \hline state & ON Switches & Voltage \\
\hline 1 & $\mathrm{Sd}, \mathrm{Sad}$ & $V_{a n}=V_{d c}, V_{d n}=V_{d c}$ \\
2 & $\mathrm{Sad}, \mathrm{Sd}$ & $V_{a n}=0, V_{d n}=0$ \\
3 & $\mathrm{Sa}, \mathrm{Sd}$ & $V_{a n}=V_{d c}, V_{d n}=0$ \\
\hline \hline
\end{tabular}

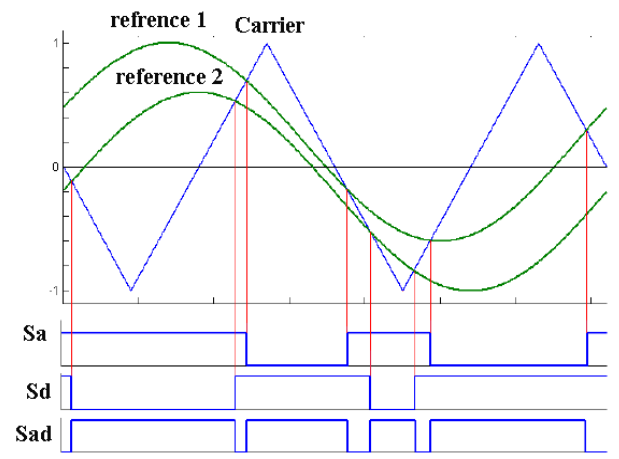

Fig. 4. Modulation for one leg.

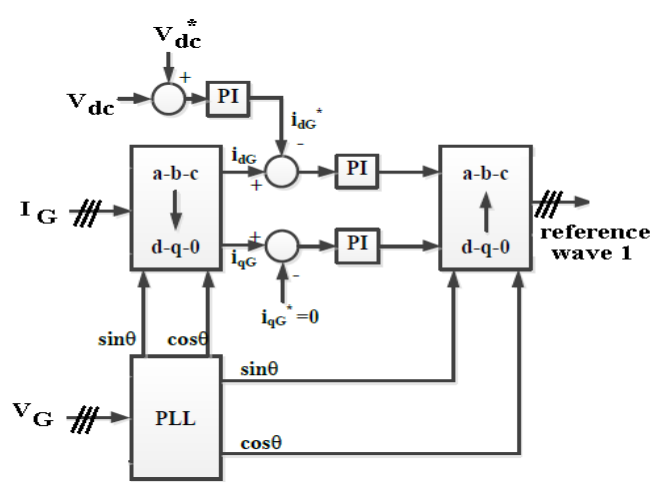

(a)

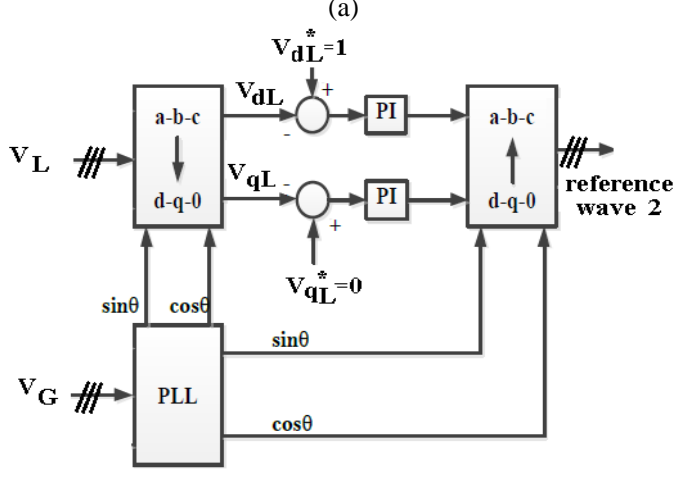

(b)

Fig. 5. Control block diagram of nine-switch inverter (a) inverter1 and (b) inverter2.
In stand-alone control mode, the output voltages need to be controlled in terms of amplitude and frequency and thus the reactive and, respectively, active power flow is controlled. In this state, voltage at inverter output $\left(V_{L}\right)$ is measured and transformed to d-q frame using Park transformation. Resultant values are compared with reference values $\left(V_{d L}^{*}=1\right.$, $\left.V_{q L}^{*}=0\right)$, the error signal is passed through PI controllers and transformed again to $a b c$ frame by Park inverse-transformation. Finally the reference voltage is applied to modulation unit to produce switching signals.

\section{SimUlation RESUlTS}

To show the performance of the proposed converter, some cases are simulated by using MATLAB/SIMULINK software. The main parameters used in simulation are listed in Table II.

Fig. 6 shows PV voltage and dc-link voltage. The dc/dc converter increases voltage of PV to reach suitable voltage of dc-link.

Fig. 7 shows power exchange of proposed system. When power of PV is bigger than power of load, the remain power is injected to grid. When power of PV is smaller than power of load, the required power is provided from grid. The power of PV is changed by changing of Irradiance.

The voltage and current of load are shown in Fig. 8.

TABLE II: SIMULATION PARAMETERS

\begin{tabular}{ll} 
& TABLE II: SIMULATION PARAMETERS \\
\hline \hline Parameter & Value \\
\hline PV system & $25 \mathrm{KW}$ in $G=1000 \mathrm{~W} / \mathrm{m}^{2}$ and $T=25^{\circ}$ \\
dc/dc converter & $L_{1}=L_{2}=500 \mu \mathrm{H}, C_{1}=C_{2}=100 \mu \mathrm{f}, f_{s}=25 \mathrm{KHz}$ \\
Inverter & DC link voltage: $1200 \mathrm{~V}$, switching frequency $5 \mathrm{KHz}$ \\
Grid & $380 \mathrm{~V}, 50 \mathrm{~Hz}$ \\
Load & $18 \mathrm{KW}$ \\
\hline \hline
\end{tabular}

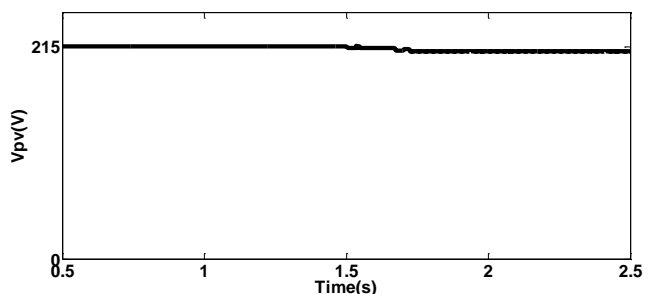

(a)

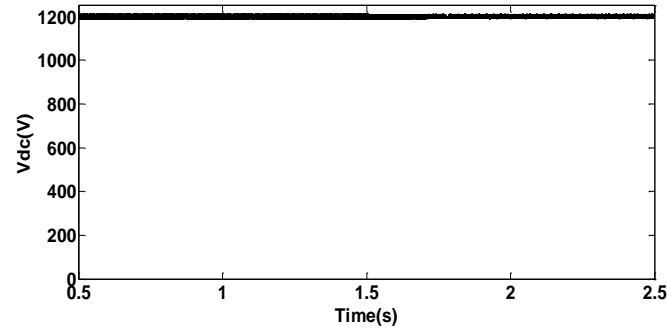

(b)

Fig. 6. (a) PV voltage and (b) dc-link voltage.

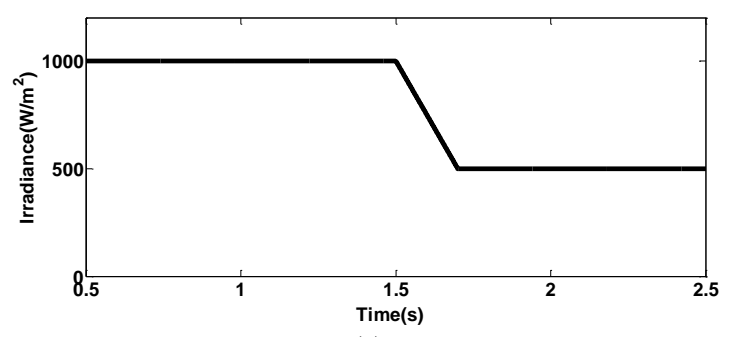

(a) 


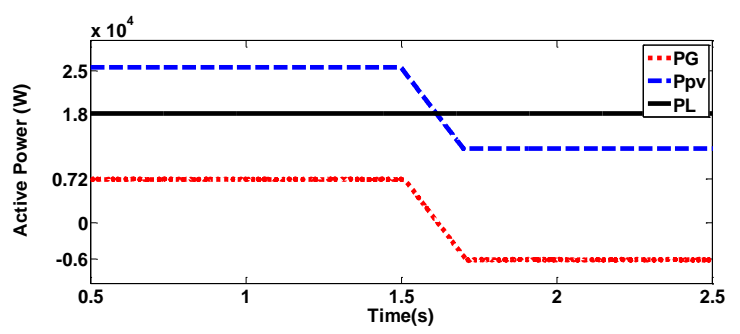

(b)

Fig. 7. Power exchange.

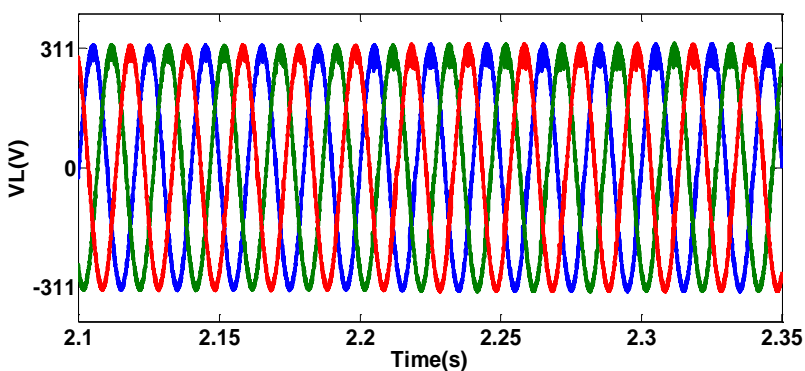

(a)

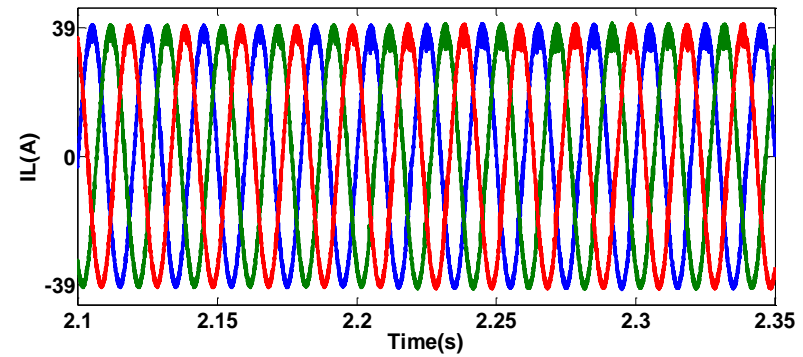

(b)

Fig. 8. Voltage and current of load (a) voltage and (b) current.

\section{CONCLUSION}

In this paper, multi-stage converter based on combination of novel dc/dc converter and the nine-switch inverter is proposed. The nine-switch converter has two output ports. The proposed dc/dc converter has high gain. The presented systems connect photovoltaic energy sources to load and grid. In proposed structure photovoltaic source inject energy to load and grid. The presented structure dose not battery system to reserve energy. The simulation results show ability of presented systems in power generation.

\section{REFERENCES}

[1] S. Danyali, S. H. Hosseini, and G. B. Gharehpetian, "New extendable single-stage multi-input dc-dc/ac boost converter," IEEE Trans. Power Electron., vol. 29, no. 2, pp. 775-788, 2014.

[2] A M. El-Sayed, M. Orabi, and O. M. A. Rahim, "Two-stage micro-grid inverter with high-voltage gain for photovoltaic applications," IET Power Electron., vol. 6, no. 9, pp. 1812-1821, 2013.
[3] Y. H. Liao and C. M. Lai, "Newly-constructed simplified single-phase multistring multilevel inverter topology for distributed energy resources," IEEE Trans. Power Electron., vol. 26, no. 9, pp. 2386-2392, 2011

[4] X. Xiong and J. Ouyang, "Modeling and transient behavior analysis of an inverter-based microgrid,” Electr. Power Compon. Syst., vol. 40, pp. 112-130, 2012.

[5] G. T. Heydt, M. Kezunovic, P. W. Sauer, A. Bose, J. D. McCalley, C. Singh, W. T. Jewell, D. J. Ray, and V. Vittal, "Professional resources to implement the smart grid," in Proc. North American Power Symposium, 2009, pp. 1-8.

[6] T. Kominami and Y. Fujimoto, "A novel nine-switch inverter for independent control of two three-phase loads," in Proc. Industry Applications Conference, 2007, pp. 2346-2350.

[7] C. Liu, B. Wu, N. Zargari, and D. Xu , "A novel nine-switch PWM rectifier-inverter topology for three-phase UPS applications," in Proc. European Conference on Power Electronics Applications, Sep. 2007.

[8] X. Liu, P. Wang, P. C. Loh, and F. A. Blaabjerg, "Three-phase dual-input matrix converter for grid integration of two AC type energy resources," IEEE Trans. Ind. Electron., vol. 60, pp. 20-30, 2013.

[9] F. Gao, L, Zhang, D. Li, P. C. Loh, Y. Tang, and H. Gao, "Optimal pulse-width modulation of nine-switch converter," in Proc. International Conference on Power Electronics and Drive Systems, Taiwan, 2009, pp. 718-723.

[10] G. Carannante, C. Fraddanno, M. Pagano, and L. Piegari, "Experimental performance of MPPT algorithm for photovoltaic sources subject to inhomogeneous insolation," IEEE Trans. Ind. Electron., vol. 56, no. 11, pp. 4374-4380, Nov. 2009.

[11] N. Femia, G. Petrone, G. Spagnuolo, and M. Vitelli, "Perturb and observe MPPT technique robustness improved," in Proc. IEEE Int. Symposium of Ind. Electron., 2004, vol. 2, pp. 845-850.

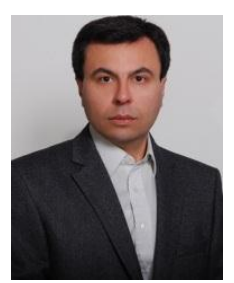

Mohamad Reza Banaei was born in Tabriz, Iran. He received his M.Sc. degree from the Poly Technique University of Tehran, Iran, in control engineering in 1999 and his Ph.D. degree from the Electrical Engineering Faculty of Tabriz University in power engineering in 2005. He is an associate professor in the Electrical Engineering Department of Azarbaijan Shahid Madani University, Iran, which he joined in 2005. His main research interests include the modeling and controlling of power electronic converters, renewable energy, modeling and controlling of FACTS and custom power devices and power systems dynamics.

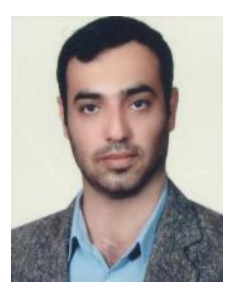

Ebrahim Salary was born in Khoram Abad, Iran. He received his B.S. degree in power electrical engineering from Dezful Azad University, Dezful, Iran, in 2004 and his M.S. degree from Tarbiat Moallem University of Azarbaijan, Tabriz, Iran, in 2010. He is a Ph.D. student in Azarbaijan Shahid Madani University, currently. His main research interests are dynamic and steady state modeling and analysis of power electronic converters, harmonics and power quality compensation systems, microprocessors, and renewable energy. 